\title{
Can Humans Dream of Electric Sheep?
}

James Michael MacFarlane: Transhumanism as a New Social Movement: The Techno-Centred Imagination. Palgrave Macmillan, 2020, 239pp, € 72,79 HB

Steven Umbrello

Steven.umbrello@unito.it

Institute for Ethics and Emerging Technologies

Università degli Studi di Torino

Torino, Italia

As an idea, transhumanism has received increasing attention in recent years and across numerous domains. Despite presidential candidates such as Zoltan Istvan, who ran on an explicitly Transhumanist platform in 2016 but later dropped out to endorse Hillary Clinton, transhumanism has taken root more recently in the conspiratorial imaginations of the dark web. Given the philosophy's central emphasis on technology as an inherent good, imaginations in supposed altright internet circles have criticised it as an ideological gateway to global, fully-automated Communism. This is not to say that such discussions on transhumanism are exclusively siloed and on the margins of society. Related discussions are happening at various well-known institutions and research centres such as the Institute for Ethics and Emerging Technologies, a non-profit think tank dedicated to techno-progressivism where I have been managing director for half a decade. What I mean to say here is that transhumanism is not monolithic. It is best described as multi-faceted and existing in different instantiations across multiple domains. James Michael MacFarlane's recent book, Transhumanism as a New Social Movement: The Techno- 
Centred Imagination, is an attempt to trace the history, meaning, and practices that characterise this variegated term.

In what is essentially an ethnographic study, MacFarlane employs some methods characteristic of the social sciences and cultural anthropology, for example, multi-sited participant observations, qualitative interviews, and surveys. These are used to determine what transhumanism means and to whom. In constructing how proponents of transhumanism selfidentify, the volume builds on Social Movement Theory (SMT) to examine the history of the philosophy's internal and external commonalities and divergences. It essentially tracks the kinetics of transhumanism, given that its adoption by different peoples and groups is plural. Because it is difficult to encompass so many different understandings of transhumanism within a single term, the use of SMT is employed as a methodology to aid others in better understanding his thesis that Transhumanism is a movement "centred around Technological Human Enhancement Advocacy (THEA)" (15).

In his ethnographic exploration, MacFarlane maintains the detached observer posture by situating the narratives of his subjects within a larger humanist tradition while also grounding these narratives as a function of current technological trends. These trends appear to substantiate and buttress a techno-utopianism often espoused by the most ardent supporters of the movement. Dividing the work into eight chapters, MacFarlane begins by laying out the problem of understanding transhumanism per se as a function of its many instantiations. In traditional academic fashion, he follows with a relatively standard literature review that aims to determine how the scholarship on transhumanism defines the term. But the scholarship is admittedly wanting, reiterating the difficulty in nailing down what the movement is in a sufficiently comprehensive way. 
Drawing on the methodology of SMT as a means for framing his study, MacFarlane proposes situating the philosophy as a 'new' social movement to address this lacuna in scholarship. He follows by explaining his chosen demographics, which he analyses in the frame of politics and religion as well as the various strengths or limits to his approach. Much of the fervour embodied by supporters of the movement seems to identify technology as more than simply the liberator of human limits, a common thread connecting many of its different embodiments across political divides. For them, technology is also the only means through which humans can confront the existential threats facing humanity today. Here, MacFarlane lays this perspective and its various flavours at the feet of intensifying tensions arising from modern post-industrial society.

This argument seems to be directly in line with Nolan Gertz's thesis on technological nihilism, although it is never explicitly referenced. Technological nihilism involves a subsequent desire to overcome human limits, in the Nietzschean sense, which seems to arise as a consequence of information saturation and overload (Gertz 2018). MacFarlane demonstrates his ability to synthesize large quantity of qualitative data to construct his argument without any verbose obtuseness or bogging the reader down with distracting data points. Still, the academic rigour is maintained and balanced with both relevant and recent citations along with thorough reference lists following each chapter that make for easy cross reference.

All in all, MacFarlane's volume is easy to read. The volume is, in fact,-a rebranding of his doctoral thesis completed at the University of Warwick's department of philosophy (MacFarlane 2018). This is significant given that this also happens to be home to the father of social epistemology and ardent transhumanist scholar Steve Fuller, who is also the editor of the series in which this volume is published. That being said, MacFarlane seems remarkably able to 
keep a healthy distance from the various brands of transhumanism as he carefully weaves the threads connecting their philosophical substructure together. Despite Fuller's position as a dominant figure in his institution and a luminary of transhumanist thought, credit is owed to MacFarlane for not revealing any of his own inclinations regarding the philosophy. As a good ethnographer, he provides his observations and their analysis as objectively as possible.

Transhumanism as a New Social Movement is able to draw on what is an undeniably large corpus of scholarship on the topic, filtering it through on-the-ground ethnographic observations and surveys and interviews with citizens. In doing so, MacFarlane dances between politics, sociology, philosophy, and religion to uncover the ties between what is often seen as a ragtag collection of eclectic thinkers. The volume positions itself as an ideal primer, not only for those unfamiliar with the topic, but also to researchers who may be interested in beginning their own observations with the state-of-the-art.

\section{References}

Gertz, N. Nihilism and technology. Rowman \& Littlefield, (2018).

MacFarlane, J.M. The Techno-centred Imagination: A Multi-sited Ethnographic Study of Technological Human Enhancement Advocacy (THEA) (Doctoral dissertation, University of Warwick) (2018). 